\title{
Design and Analysis of Rectangular Microstrip Antenna using Slotted Substrate Structure to Minimize Fabrication Error
}

\author{
Sudarshan Kumar Jain, Sandeep Toshniwal, Dr.Rajesh Purohit
}

\begin{abstract}
A wide band rectangular microstrip patch antenna with resonant frequency variation characteristics using slotted substrate structure is proposed in this paper. The antenna is designed at a frequency of $5 \mathrm{GHz}$ and it has wide band characteristics. Here the different resonant frequencies are received due to slotted substrate structure of the antenna. Slotted substrate structure changes the effective dielectric constant of the substrate. The antenna is energized using the microstrip line feeding method. VSWR of the designed rectangular patch antenna is less than 2 . The different characteristics of the antenna such as return loss, gain, directivity, bandwidth, radiated field and VSWR is analysed for different sizes of the slots made in the dielectric substrate of the antenna. It is observed that the designed antenna gives the various resonant frequencies for the different sizes of the slots made in the antenna substrate. So this antenna can be used to minimize the fabrication error in the designed antenna without varying the patch size. Duroid is used as substrate material for the designing of the antenna. The antenna design is simulated by using the High Frequency Structure Simulator (HFSS) software.
\end{abstract}

Keywords- Microstrip antenna, Resonant Frequency, Microstrip feeding, HFSS, VSWR

\section{INTRODUCTION}

Microstrip Patch antennas have many applications such as antenna for high speed vehicles, missile tanks, satellite communication and other strategic defence equipments. Numerous advantages of microstrip antenna over the conventional microwave antenna such as light weight, low cost, low volume, planar configuration and compatibility with integrated circuits associated with diversified application have observed by the researchers. It is expected that microstrip antenna will alternately replace the conventional microwave antennas for most of the application in future.

A microstrip patch antenna consists a sandwich of two parallel conducting layers separated by a single dielectric substrate as shown in fig. 1

The patch conductors are normally of copper and gold. The lower conductor works as a ground plane and the upper conductor may be a simple patch of any desired shape. The conventional shape of the patch is rectangular, circular, square, triangular, elliptical etc. The $\varepsilon_{\mathrm{r}}$ of the substrate should be low in order to enhance the fringing fields which are responsible for most of the radiations from the patch. Radiation in microstrip antenna occurs from the fringing fields existing at the open circuited end or edges of the patch. The fringing fields at the two open circuited ends of the patch can be resolved in two components: one normal to the ground plane and the other parallel to the ground plane.

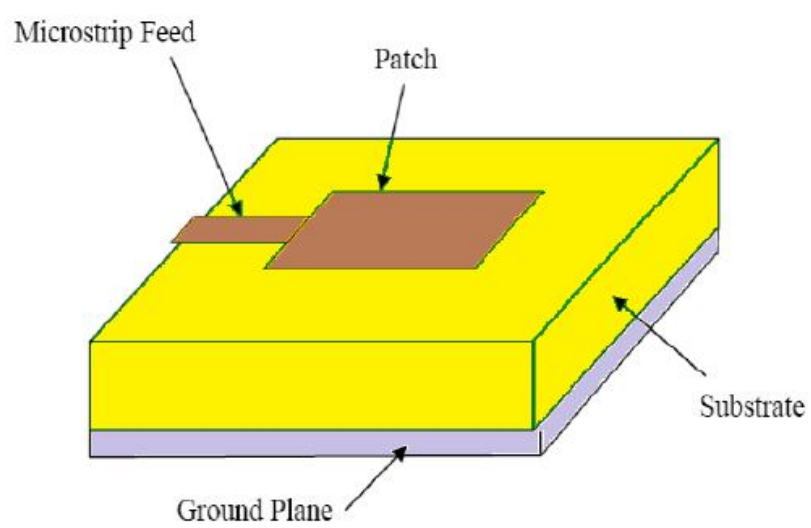

Fig. 1 Microstrip patch antenna structure

\section{ANTENNA DESIGN}

The antenna is designed and analysed at a resonant frequency of $5 \mathrm{GHz}$ for the different sizes of the slots made in the antenna substrate. The substrate used for the designing of the antenna is duroid having dielectric constant of 2.2.

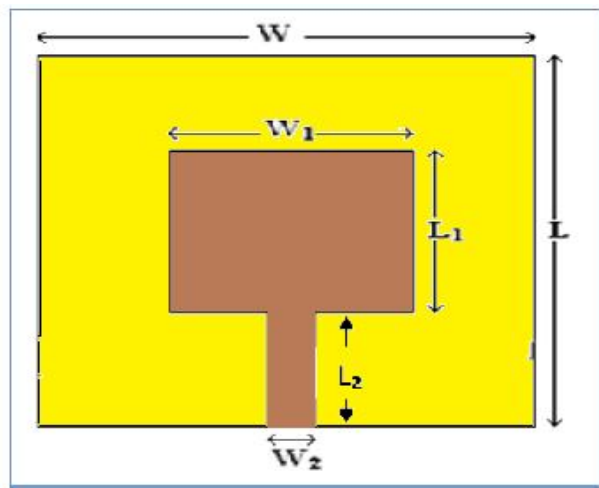

Fig. 2 Geometry of Rectangular Microstrip Patch antenna 
The antenna is designed using duroid material as dielectric substrate with dielectric constant $\varepsilon_{\mathrm{r}}=2.2$, and thickness $\mathrm{h}=1.6$ $\mathrm{mm}$. The antenna is designed to operate at a frequency of 5 GHz. The substrate has a compact size of $28.36 \mathrm{~mm} \times 26.96$ $\mathrm{mm}$ as shown in fig.3.3. In order to fulfil the requirements of a portable device, a microstrip feed line is designed for $50 \Omega$ characteristic impedance with $3 \mathrm{~mm}$ width. The first step to design a rectangular patch antenna is to compute its physical dimensions. The effective dielectric constant, physical width and length are calculated using design equations. Various optimized parameters of antenna are $\mathrm{W}=26.96 \mathrm{~mm}$, $\mathrm{W}_{1}=19.3 \mathrm{~mm}, \quad \mathrm{~W}_{2}=3 \mathrm{~mm}, \quad \mathrm{~L}=28.36 \mathrm{~mm}, \quad \mathrm{~L}_{1}=23.72 \mathrm{~mm}$, $\mathrm{L}_{2}=8.2 \mathrm{~mm}$. Fig. 3 and fig. 4 shows the actual HFSS design for the designed antenna and flow chart respectively.

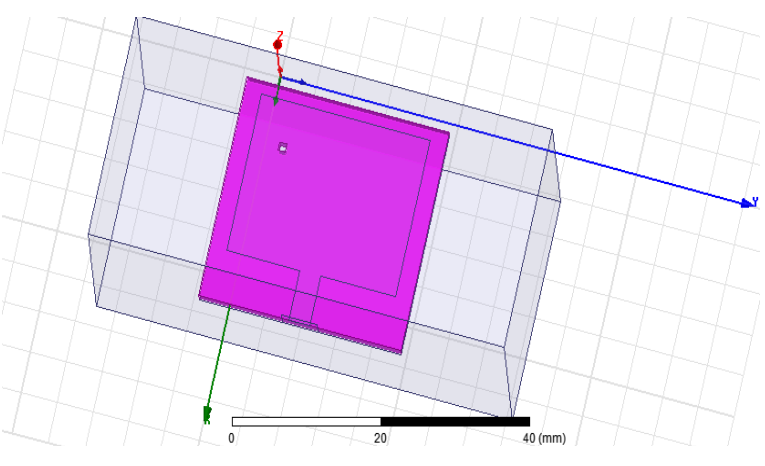

Fig.3 Actual HFSS design of antenna

Here the antenna design is simulated for the various sizes of the rectangular and the square slots made in the dielectric substrate. Due to the change in effective dielectric constant of the substrate the resonant frequency of the antenna changes. A ratio between the area of slot to the area of patch (As/Ap) is also calculated for finding out the percentage change in resonant frequency of the antenna since the area of patch is constant.

For each slot size and resonant frequency the designed antenna is simulated using HFSS for the various properties of antenna such as gain, directivity, return loss, voltage standing wave ratio and radiated E field etc. All the parameters are compared for the different slot sizes made in the substrate. The resonant frequency of the antenna is analysed for both conventional structure and the slotted substrate structure. From the simulated results it is found that the antenna has different resonant frequencies for the different sizes of the slot which can be used to minimize the fabrication error in the antenna without varying patch size.

The different characteristics of the antenna such as return loss, gain, bandwidth, directivity, radiated field and VSWR is analysed for this designed antenna. It is observed that the different resonant frequencies are achieved for the different sizes of the slots made in the designed antenna using slotted substrate structure. The antenna design is simulated using High frequency structure simulator software.

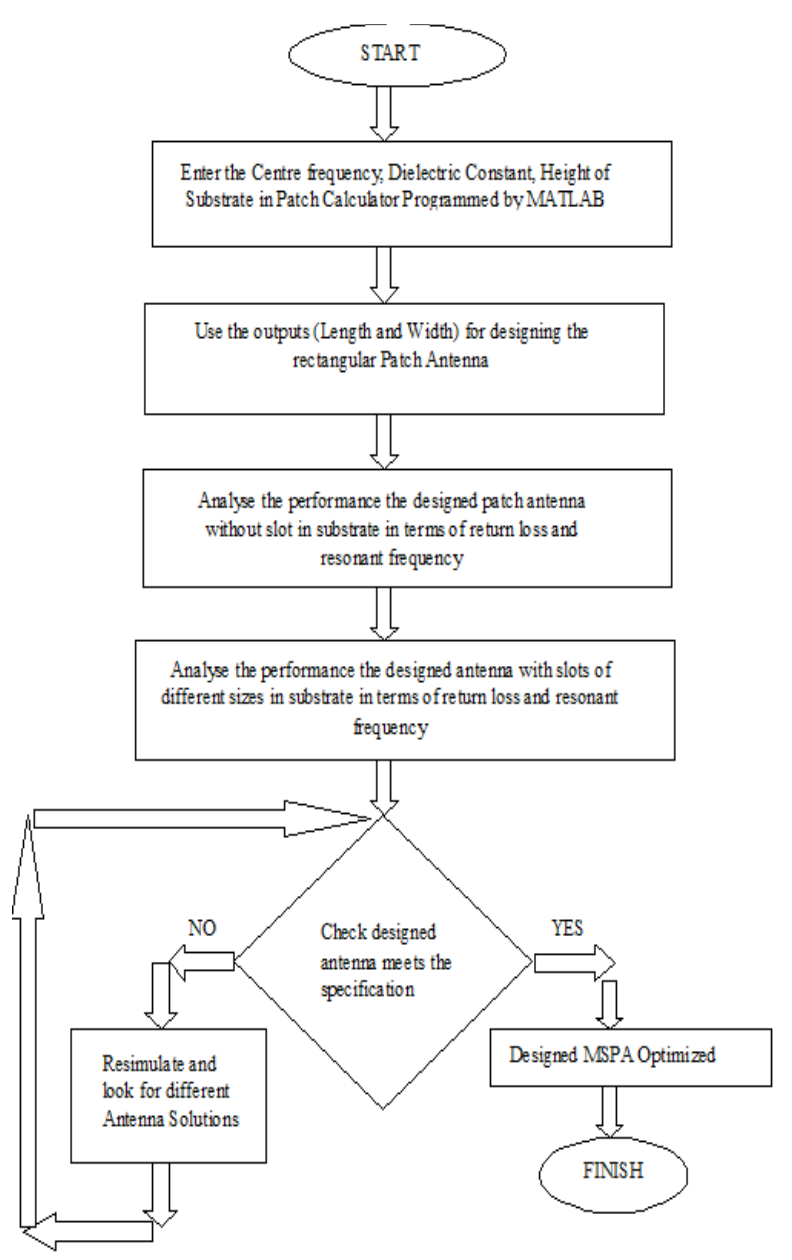

Fig.4 Flow chart for the designed antenna

TABLE 1

DESIGNED ANTENNA DIMENSIONS IN MM

\begin{tabular}{|l|l|l|l|l|l|l|}
\hline $\mathbf{W}_{\mathbf{S}}$ & $\mathbf{L}_{\mathbf{S}}$ & $\mathbf{A}_{\mathbf{S}}$ & $\mathbf{W}_{\mathbf{P}}$ & $\mathbf{L}_{\mathbf{P}}$ & $\mathbf{A}_{\mathbf{P}}$ & $\mathbf{A}_{\mathbf{S}} / \mathbf{A}_{\mathbf{P}}$ \\
\hline 1 & 1 & 1 & 19.3 & 23.72 & 457.796 & 0.00218 \\
\hline 4 & 5 & 20 & 19.3 & 23.72 & 457.796 & 0.04369 \\
\hline 7 & 7 & 49 & 19.3 & 23.72 & 457.796 & 0.10703 \\
\hline 9 & 9 & 81 & 19.3 & 23.72 & 457.796 & 0.17693 \\
\hline 10 & 10 & 100 & 19.3 & 23.72 & 457.796 & 0.21844 \\
\hline 9 & 13 & 117 & 19.3 & 23.72 & 457.796 & 0.25557 \\
\hline 11 & 11 & 121 & 19.3 & 23.72 & 457.796 & 0.26431 \\
\hline 12 & 12 & 144 & 19.3 & 23.72 & 457.796 & 0.31455 \\
\hline 13 & 11 & 143 & 19.3 & 23.72 & 457.796 & 0.31237 \\
\hline 13 & 13 & 169 & 19.3 & 23.72 & 457.796 & 0.36916 \\
\hline
\end{tabular}


Here $\mathrm{W}_{\mathrm{S}}=$ Width of the slot, $\mathrm{L}_{\mathrm{S}}=$ Length of the slot

$A_{S}=$ Area of the slot, $W_{P}=$ Width of the Patch

$L_{P}=$ Length of the Patch, $A_{P}=$ Area of the Patch

\section{RESULTS AND DISCUSSION}

The designed microstrip wide band rectangular patch antenna is simulated by using the software HFSS (High Frequency Structure simulator). The simulated results for return loss, antenna gain, VSWR, directivity, electric field are observed for the different sizes of the slots made in the antenna substrate. All the outputs of the designed antenna using slotted substrate and conventional substrate is shown below

\section{A. Simulation results without slotted substrate:}

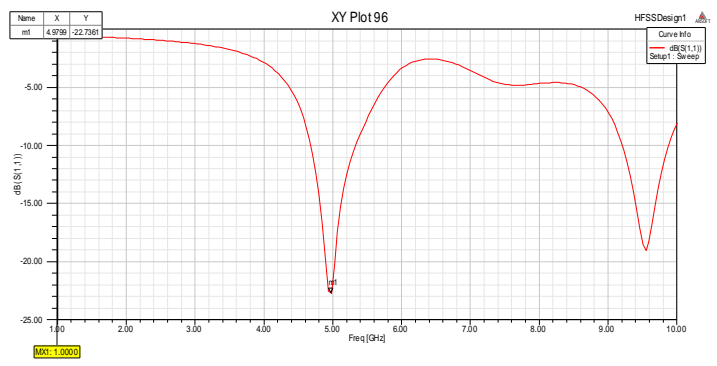

Fig.5 Return loss Vs Frequency of the antenna

It is clear from the fig. 5 that a resonant frequency of 4.9799 $\mathrm{GHz}$ when no slotted substrate is used. The minimum return loss is $-22.7361 \mathrm{~dB}$.

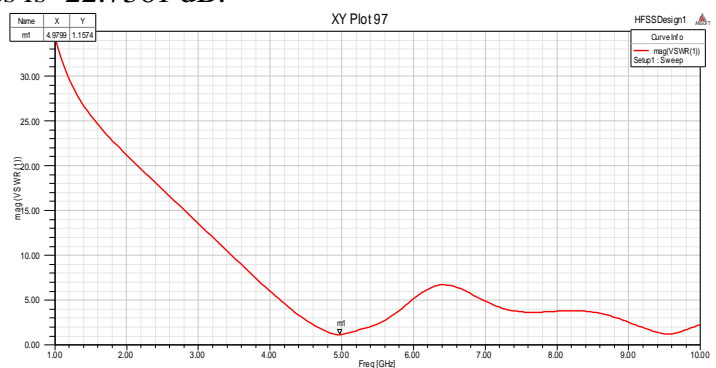

Fig.6 VSWR of the antenna

From the fig. 6 it is clear that the voltage standing wave ratio for antenna is 1.1574 or near to unity.
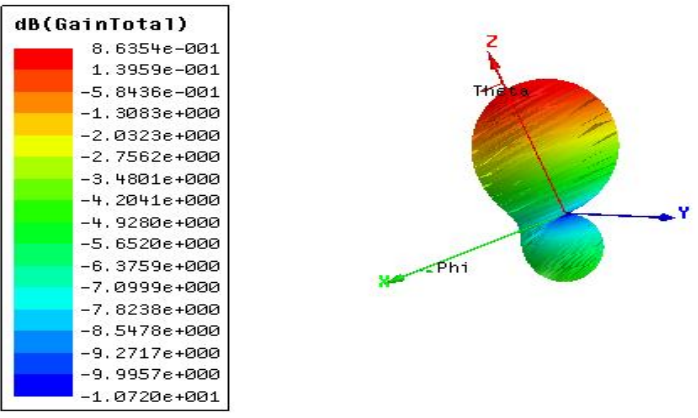

Fig.7 Gain of the antenna
Fig.7 shows that the maximum gain of the antenna is $8.635 \mathrm{~dB}$
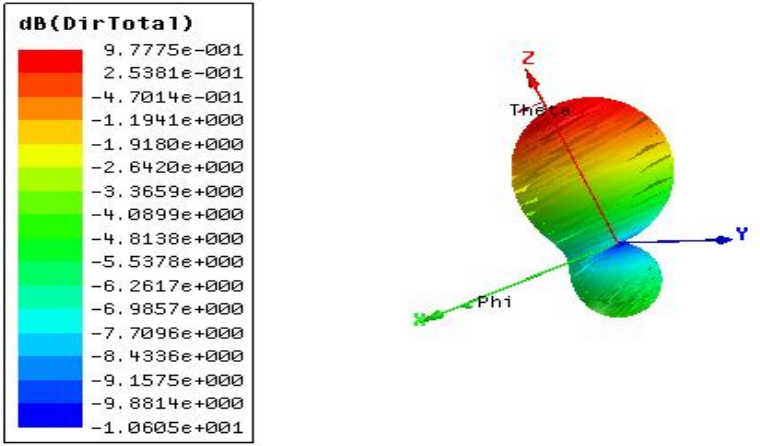

Fig.8 Directivity of the antenna

Fig. 8 shows that the maximum directivity of $9.77 \mathrm{~dB}$.

B. Simulation results with slotted substrate:

1) When slot size is $1 \mathrm{~mm} \times 1 \mathrm{~mm}$ :

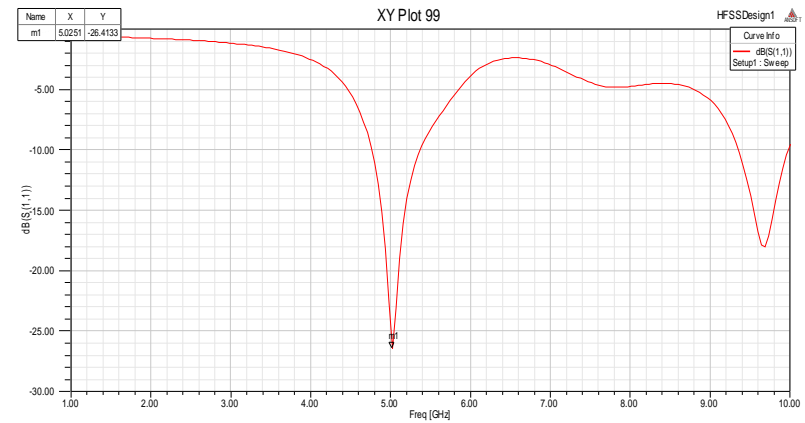

Fig.9 Return loss Vs Frequency of the antenna

According to Fig.9 resonant frequency of $5.02 \mathrm{GHz}$ is received having return loss of $26.4133 \mathrm{~dB}$.Bandwidth of the antenna at this frequency is $600 \mathrm{MHz}$.

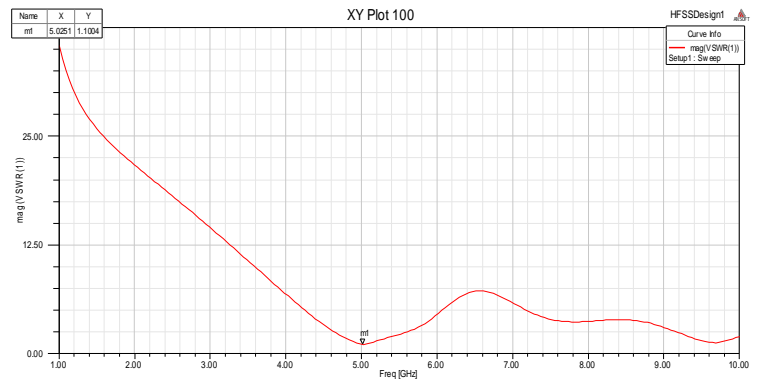

Fig.10 VSWR of the antenna

From 10 it is seen that the voltage standing wave ratio for the antenna is near to unity or it is 1.1004 . 


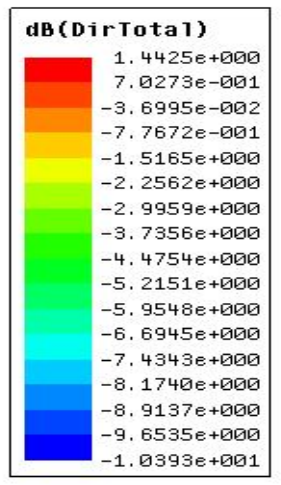

Fig.11 Gain of the antenna
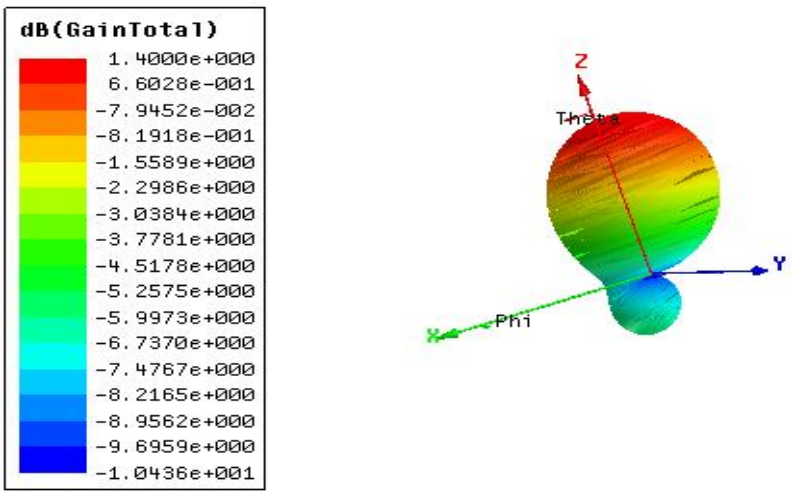

Fig.12 Directivity of the antenna

2) When slot size is $7 \mathrm{~mm} \times 7 \mathrm{~mm}$ :

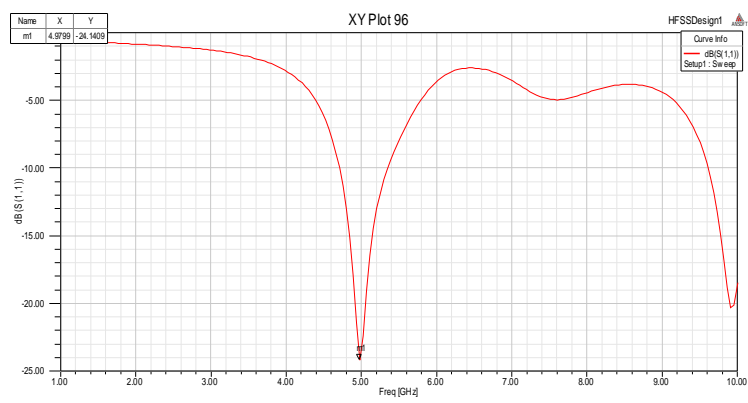

Fig.13 Return loss Vs Frequency of the antenna

According to the Fig.13 resonant frequency of the antenna is $4.9799 \mathrm{GHz}$ and the return loss is $-24.1409 \mathrm{~dB}$. Bandwidth of the designed antenna at this frequency is $636.9 \mathrm{MHz}$ so here the bandwidth is increased.

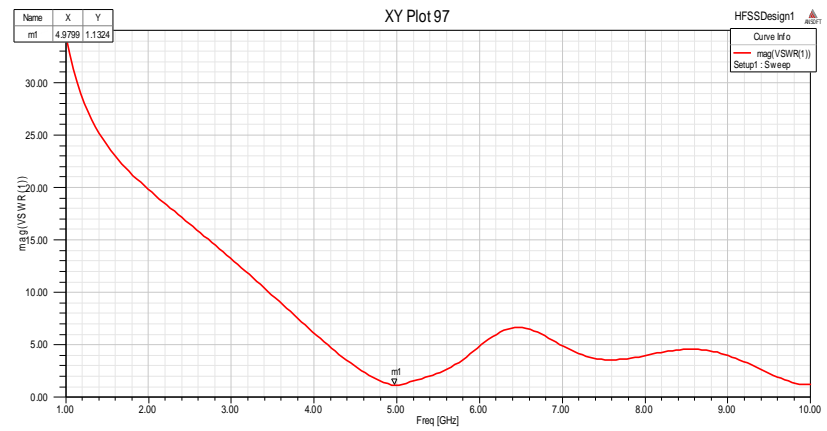

Fig.14 VSWR of the antenna

Voltage standing wave ratio for the designed antenna for the given slot size is 1.1324 , that is near to unity and gives good performance.
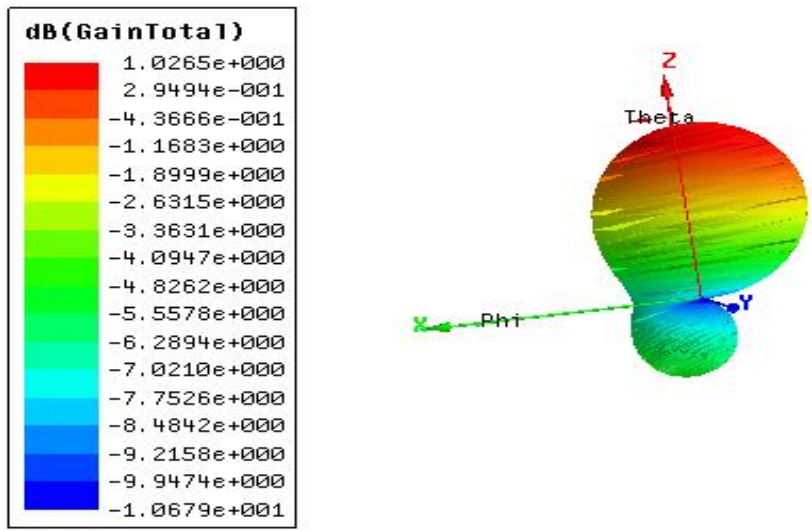

Fig.15 Gain of the antenna
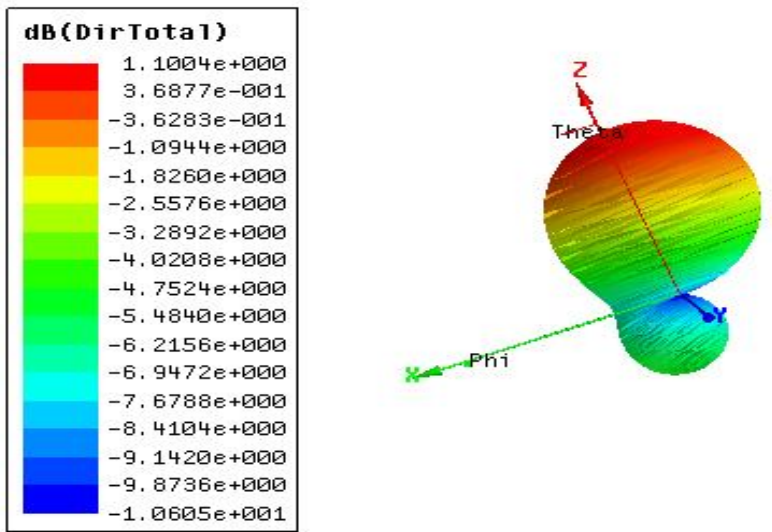

Fig.16 Directivity of the antenna 
3) When slot size is $9 \mathrm{~mm} \times 9 \mathrm{~mm}$ :

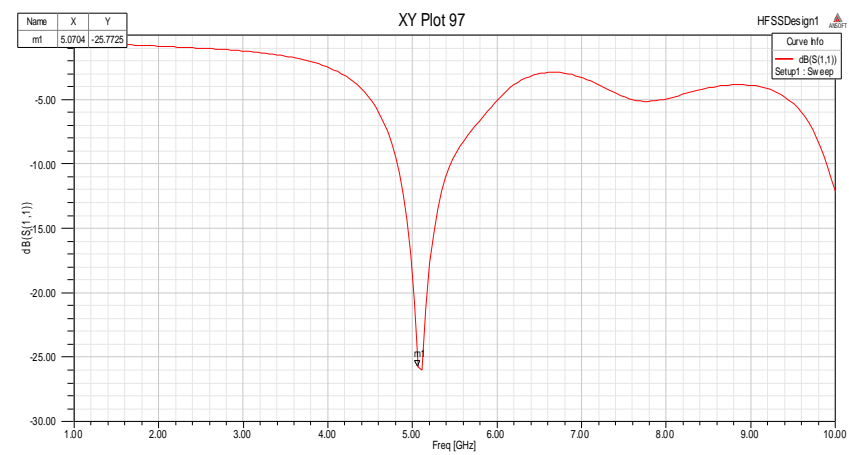

Fig.17 Return loss Vs Frequency of the antenna

According to Fig.17 resonant frequency of $5.0704 \mathrm{GHz}$ is received having return loss of $-25.7725 \mathrm{~dB}$.Bandwidth of the antenna at this frequency is $379.2 \mathrm{MHz}$.

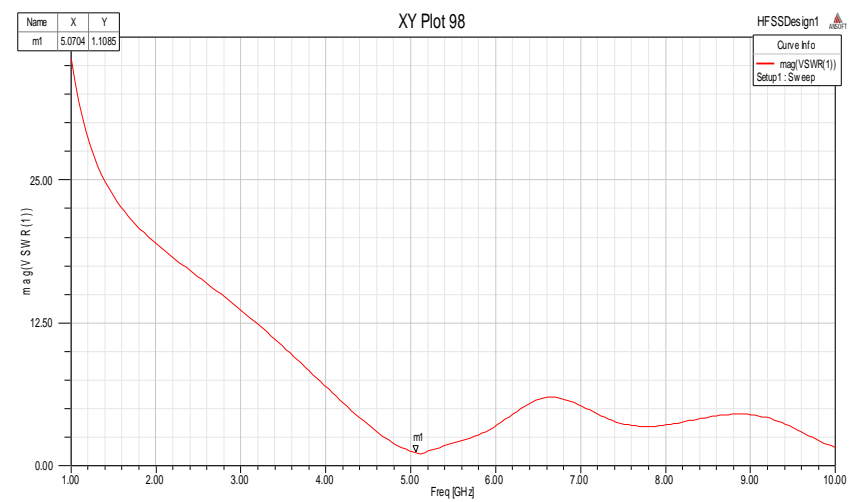

Fig.18 VSWR of the antenna

Voltage standing wave ratio for the antenna for this slot size is 1.1085 or near to unity.

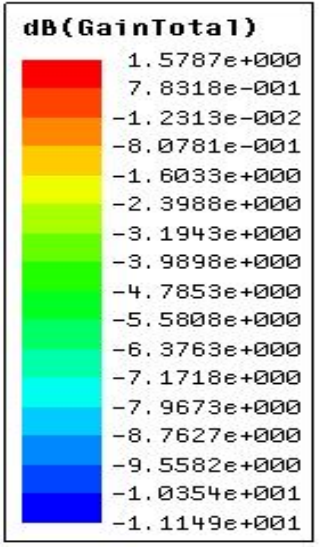

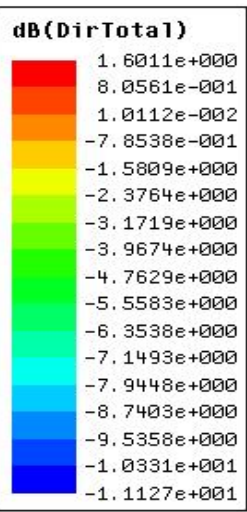

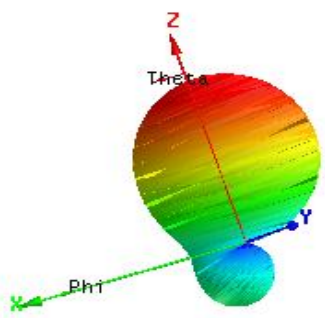

Fig.20 Directivity of the antenna

4) When slot size is $10 \mathrm{~mm} \times 10 \mathrm{~mm}$ :

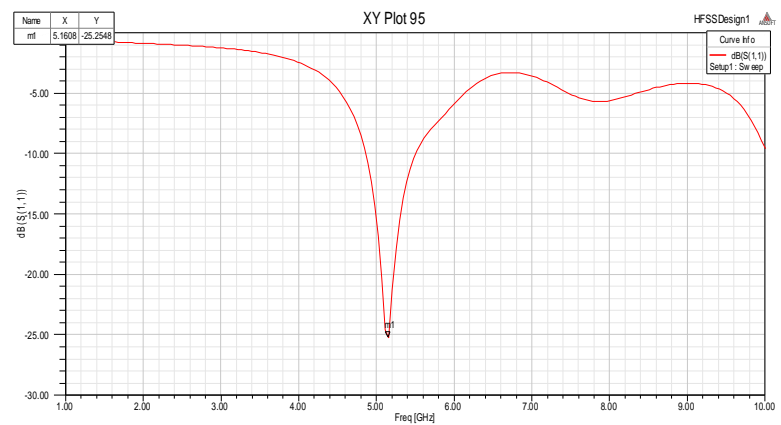

Fig.21 Return loss Vs Frequency of the antenna

Fig. 21 shows that a resonant frequency of $5.1608 \mathrm{GHz}$ is received for a return loss of $-25.2548 \mathrm{~dB}$.Bandwidth of the antenna at this frequency is $655.3 \mathrm{MHz}$.

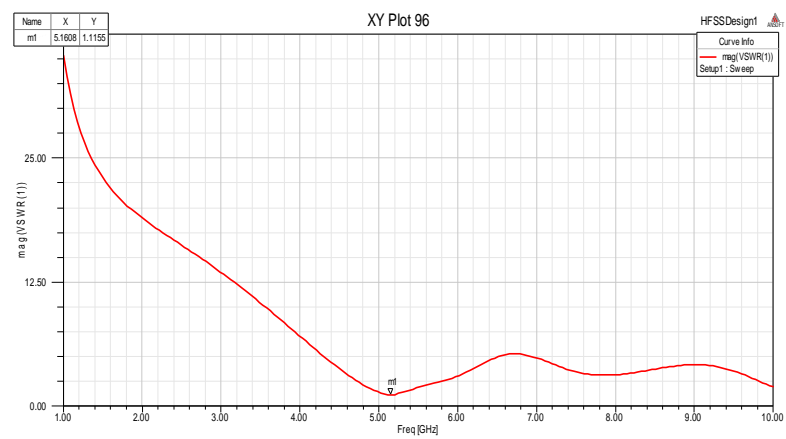

Fig.22 VSWR of the antenna

Fig.22 shows that VSWR for the designed antenna is 1.1155 .

Fig.19 Gain of the antenna 


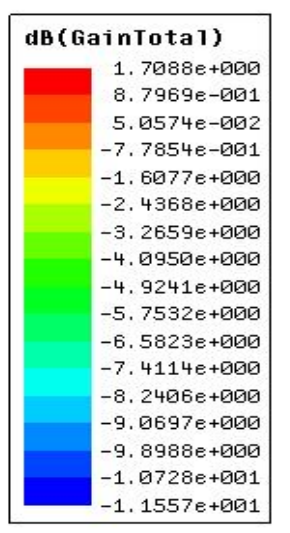

Fig.23Gain of the antenna
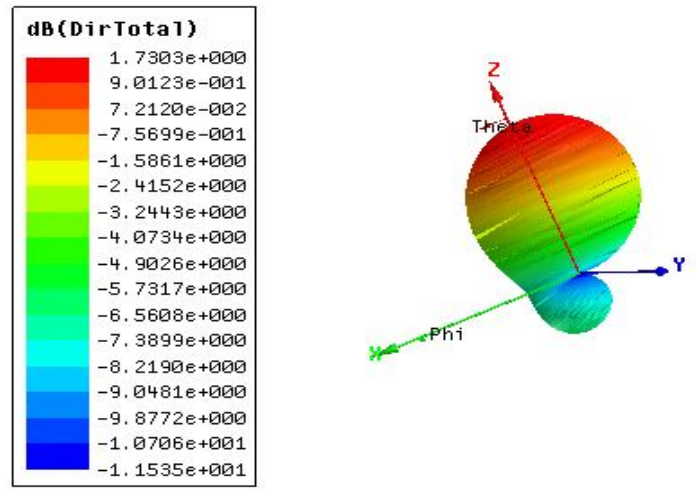

Fig. 24 Directivity of the antenna

5) When slot size is $11 \mathrm{~mm} \times 11 \mathrm{~mm}$ :

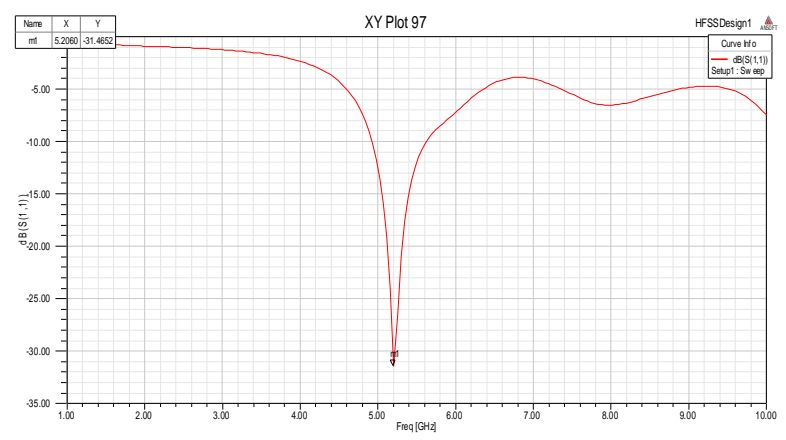

Fig.25 Return loss Vs Frequency of the antenna

Fig.25 shows that a resonant frequency of $5.206 \mathrm{GHz}$ is received for a return loss of $-31.4652 \mathrm{~dB}$. Bandwidth of the antenna at this frequency is $701.5 \mathrm{MHz}$.

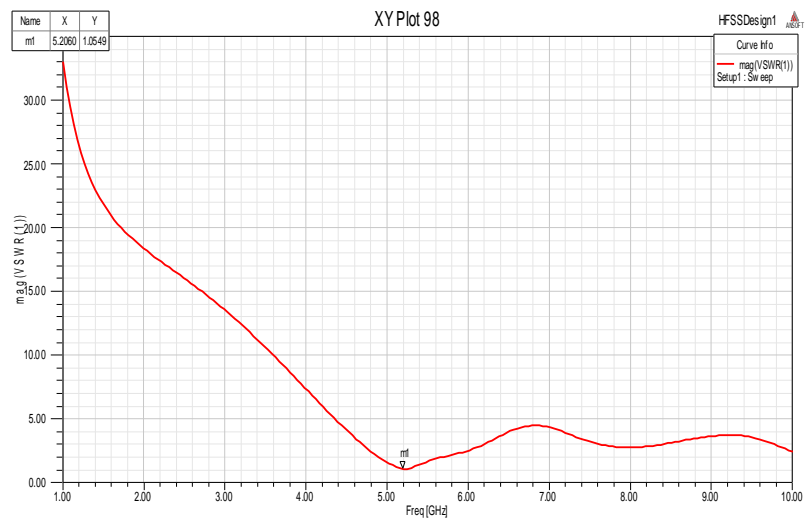

Fig.26 VSWR of the antenna

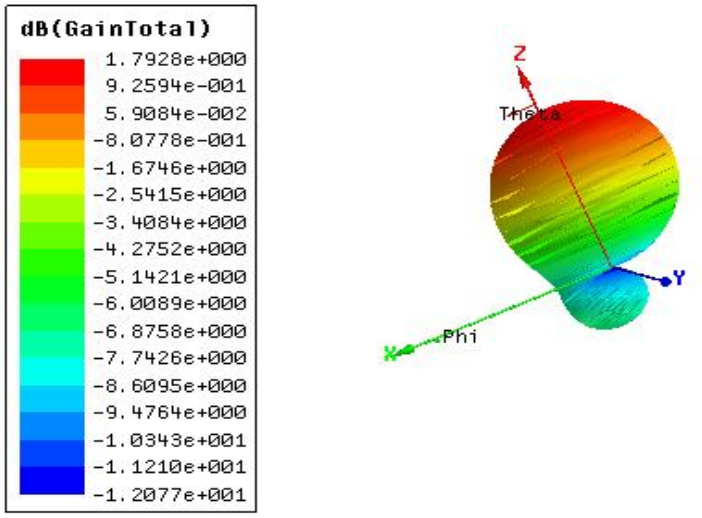

Fig.27 Gain of the antenna

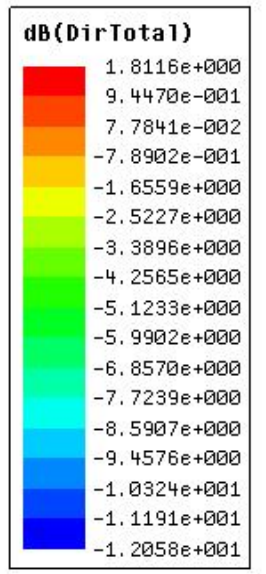

Fig.28 Directivity of the antenna 
6) When slot size is $12 \mathrm{~mm} \times 12 \mathrm{~mm}$ :

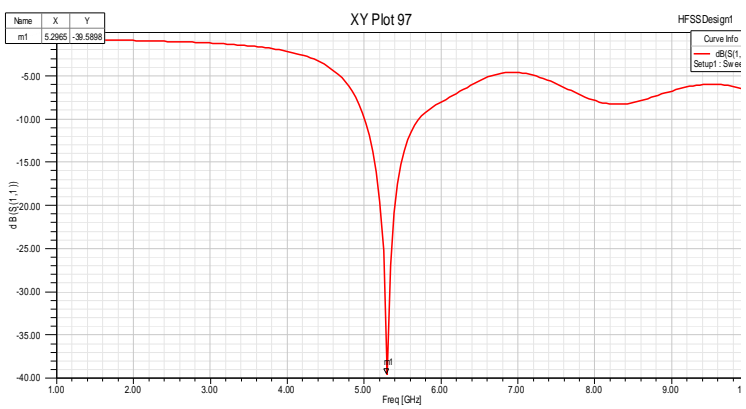

Fig.29 Return loss Vs Frequency of the antenna

According to Fig.29 resonant frequency of $5.2965 \mathrm{GHz}$ is received having return loss of $-39.5898 \mathrm{~dB}$ .Bandwidth of the antenna at this frequency is $697 \mathrm{MHz}$.

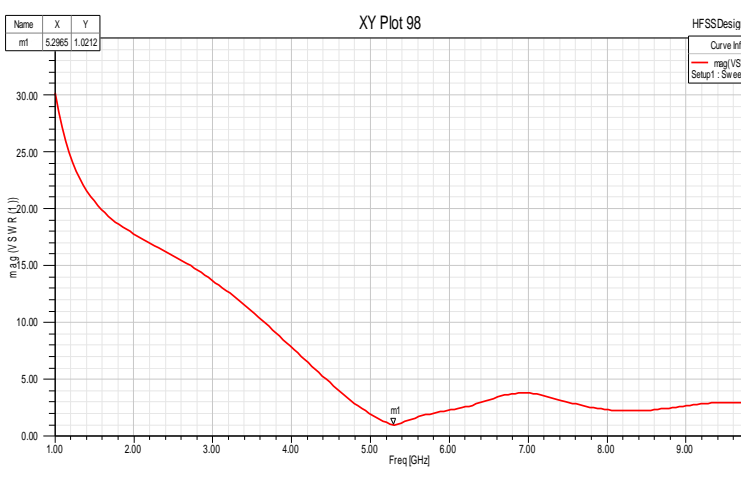

Fig.30 VSWR of the antenna

Fig.30 shows that voltage standing wave ratio for the designed antenna for the given slot size is 1.0212 .
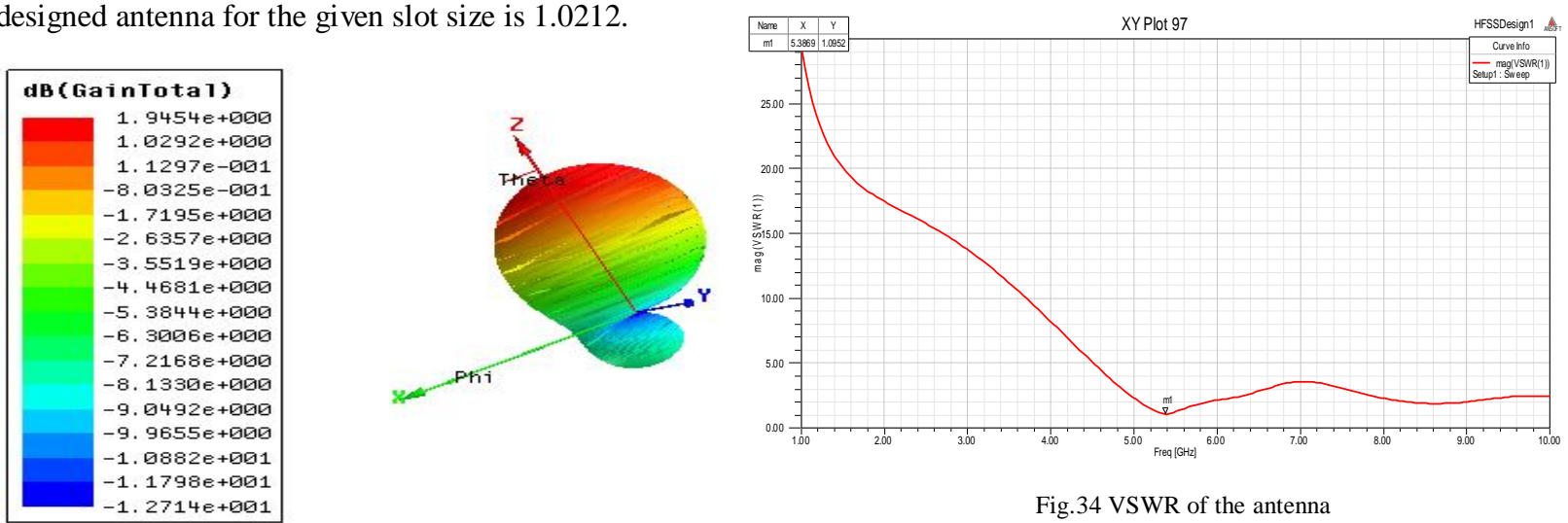

Fig.34 VSWR of the antenna

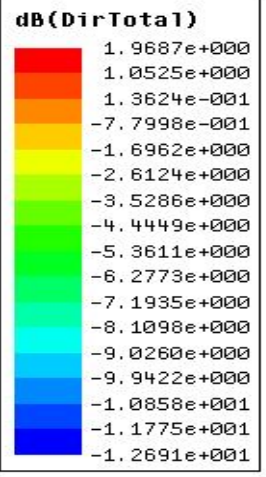

Fig.32 Directivity of the antenna

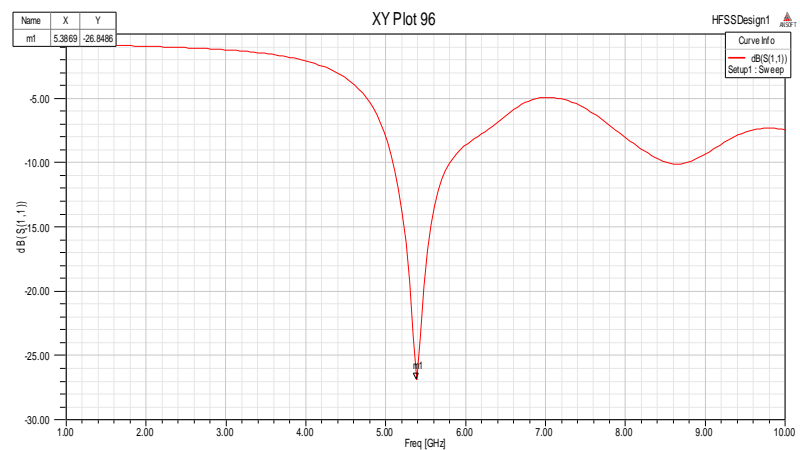

Fig.33 Return loss Vs Frequency of the antenna

Fig. 33 shows that a resonant frequency of $5.3869 \mathrm{GHz}$ is received for a return loss of $-26.8486 \mathrm{~dB}$.Bandwidth of the antenna at this frequency is $720 \mathrm{MHz}$.
7) When slot size is $13 \mathrm{~mm} \times 13 \mathrm{~mm}$ :

Fig.31 Gain of the antenna 
Fig.34 shows that voltage standing wave ratio for the designed antenna is 1.0952 at a resonant frequency of $5.3869 \mathrm{GHz}$.
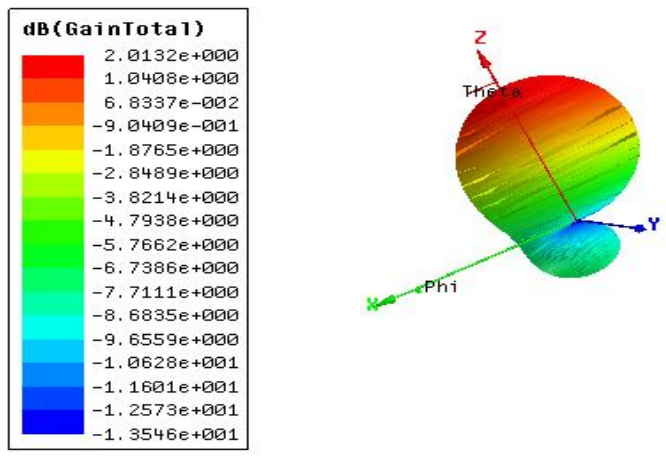

Fig.35 Gain of the antenna
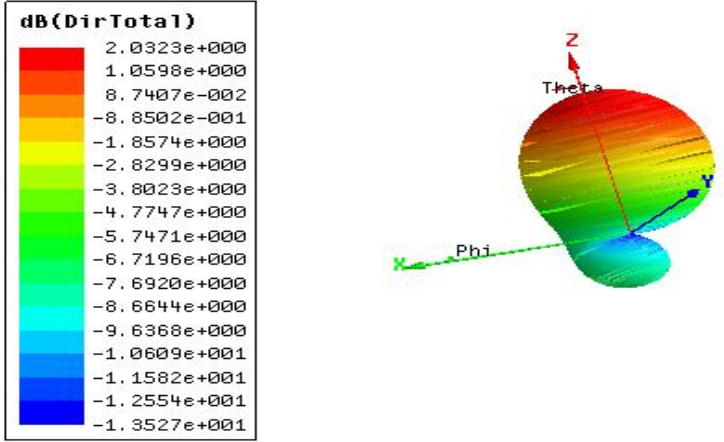

Fig.36 Directivity of the antenna

8) When slot size is $13 \mathrm{~mm} \times 11 \mathrm{~mm}$ :

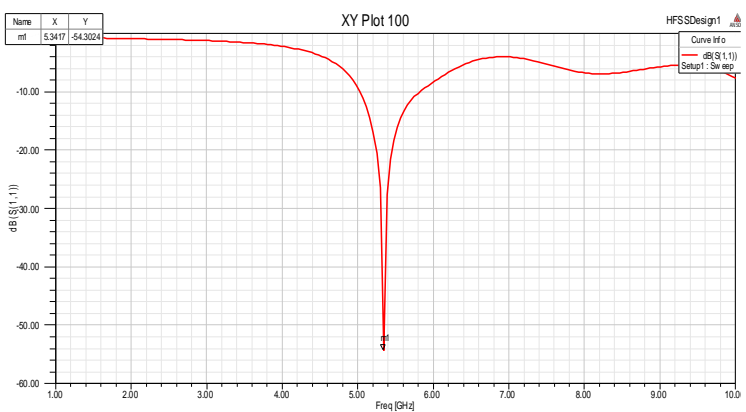

Fig.37 Return loss Vs Frequency of the antenna

According to Fig.37resonant frequency of $5.3417 \mathrm{GHz}$ is receive having return loss of $-54.3024 \mathrm{~dB}$. Bandwidth of the antenna at this frequency is $775.4 \mathrm{MHz}$.

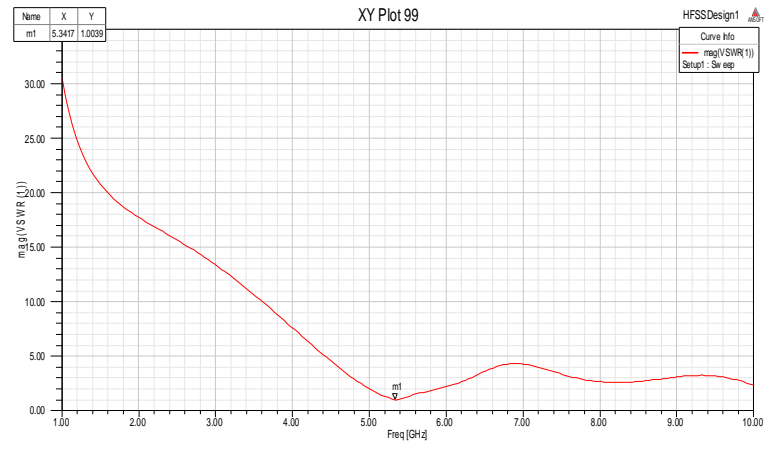

Fig. 38 VSWR of the antenna

According to Fig.38 voltage standing wave ratio for the designed antenna at resonant frequency of 5.3417 $\mathrm{GHz}$ is 1.0039 .
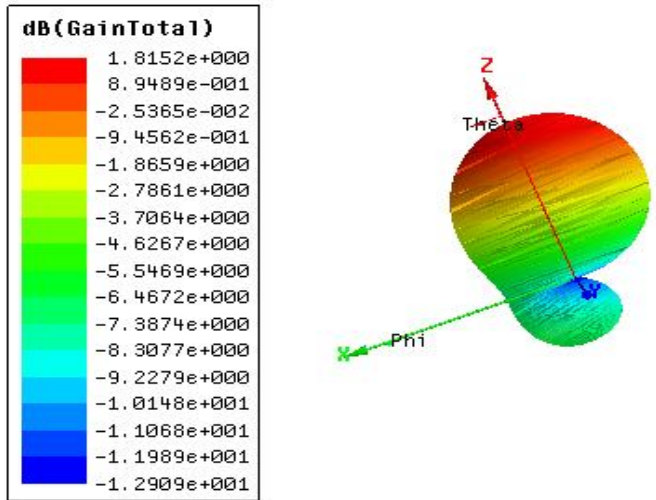

Fig.39 Gain of the antenna
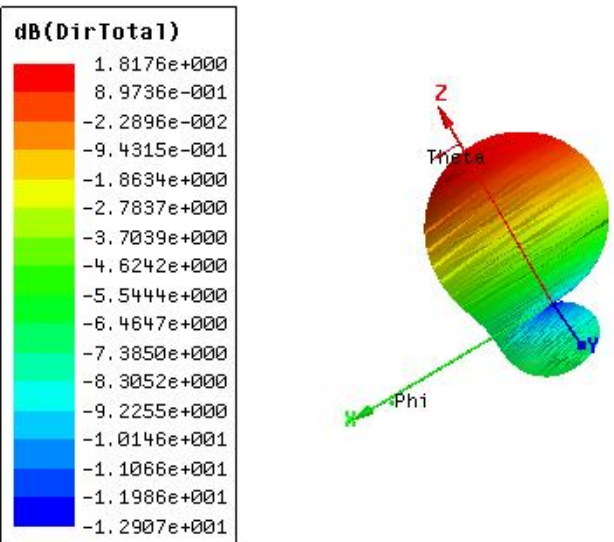

Fig.40 Directivity of the antenna 
9) When slot size is $9 \mathrm{~mm} \times 13 \mathrm{~mm}$ :

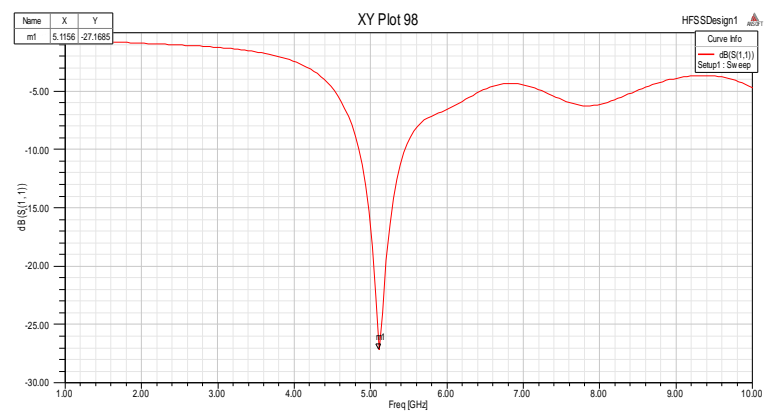

Fig.41 Return loss Vs Frequency of the antenna

Fig.41 shows that a resonant frequency of $5.1156 \mathrm{GHz}$ is received for the specified slot size and having return loss of $-27.1685 \mathrm{~dB}$.Bandwidth of the antenna at this frequency is $609.3 \mathrm{MHz}$.

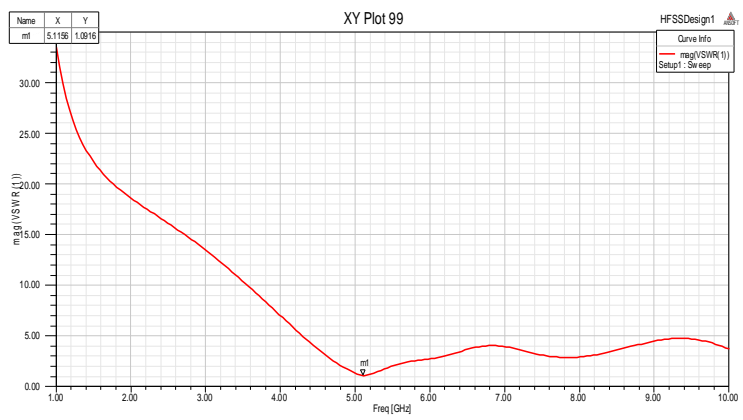

Fig.42 VSWR of the antenna

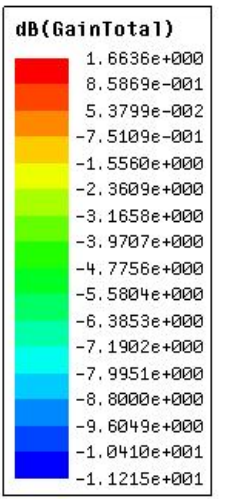

Fig.43 Gain of the antenna

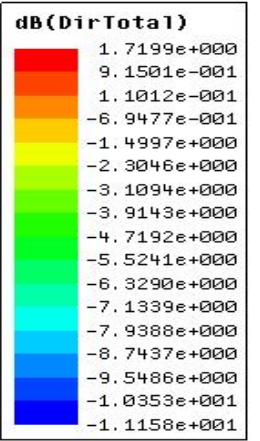

Fig.44 Directivity of the antenna

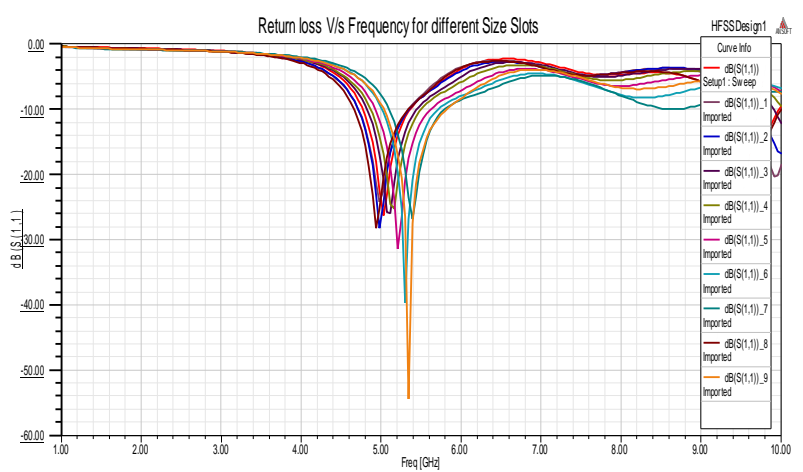

Fig.45 Return loss V/s Frequency for different size slots

Fig.45 shows the combined curve for return loss V/s frequency for different size slots made in the substrate of the designed antenna. So according to this curve various resonant frequencies are received for different size slots.

TABLE 2

COMPARISON CHART OF OUTPUTS USING SLOTTED SUBSTRATE STRUCTURE

\begin{tabular}{|c|c|c|c|c|c|c|}
\hline $\begin{array}{c}\text { Slot } \\
\text { size } \\
(\mathbf{m m})\end{array}$ & $\begin{array}{c}\text { Resonant } \\
\text { frequency } \\
(\mathbf{G H z})\end{array}$ & $\begin{array}{c}\text { Return } \\
\text { loss }\end{array}$ & $\begin{array}{c}\text { Gain } \\
(\mathbf{d B})\end{array}$ & Directivity & VSWR & Bandwidth \\
$\mathbf{( d B})$ & $\mathbf{M H z})$ \\
\hline $\mathbf{1 \times 1}$ & 5.02 & -26.41 & 1.40 & 1.44 & 1.10 & 600 \\
\hline $\mathbf{7 \times 7}$ & 4.97 & -24.14 & 2.94 & 1.10 & 1.13 & 636.9 \\
\hline $\mathbf{9 \times 9}$ & 5.07 & -25.77 & 7.83 & 8.05 & 1.10 & 379.2 \\
\hline $\mathbf{1 0 \times 1 0}$ & 5.16 & -25.25 & 8.79 & 9.01 & 1.15 & 655.3 \\
\hline $\mathbf{1 1} \times \mathbf{1 1}$ & 5.20 & -31.46 & 9.25 & 9.44 & 1.05 & 701.5 \\
\hline $\mathbf{1 2 \times 1 2}$ & 5.29 & -39.58 & 1.94 & 1.96 & 1.02 & 697 \\
\hline
\end{tabular}




\begin{tabular}{|c|c|c|c|c|c|c|}
\hline $\mathbf{1 3} \times \mathbf{1 3}$ & 5.38 & -26.84 & 2.01 & 2.03 & 1.09 & 720 \\
\hline $\mathbf{1 3 \times 1 1}$ & 5.34 & -54.30 & 8.94 & 1.82 & 1.00 & 775.4 \\
\hline $\mathbf{9 \times 1 3}$ & 5.11 & -27.16 & 1.66 & 1.71 & 1.09 & 609.3 \\
\hline $\mathbf{4 \times 5}$ & 4.93 & -28.30 & 6.79 & 7.74 & 1.07 & 692.3 \\
\hline
\end{tabular}

So according to the above relation a required resonant frequency can be achieved for specific ratio of area of slot to area of patch, since the area of patch is constant, so a slot can be inserted in the substrate of the antenna without varying the size of the patch to get the required resonant frequency.

\section{CONCLUSION}

So the antenna resonates at different different frequencies for the different sizes of the slots due to the change in

Table 2 shows the various parameter values of the antenna for the different sizes of the slots. So a curve can be drawn between the ratio (As/Ap) and the percentage change in resonant frequency value for the different size slots.

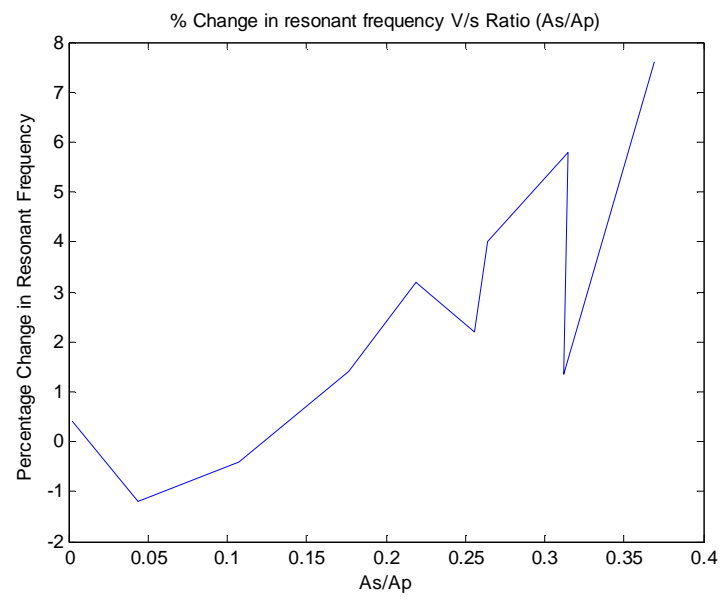

Fig.46 Change in resonant frequency Vs ratio As/Ap

So according to this curve a relation can be written for the percentage change in resonant frequency for different size slots and the ratio (As/Ap) which comes out-

$y=p 1 * x^{\wedge} 5+p 2 * x^{\wedge} 4+p 3 * x^{\wedge} 3+p 4 * x^{\wedge} 2+p 5 * x+p 6$

Where Coefficients:

$\mathrm{p} 1=16821, \mathrm{p} 2=-9340.8, \mathrm{p} 3=326.06, \mathrm{p} 4=521.73, \mathrm{p} 5=-$

$60.278, \mathrm{p} 6=0.51056$

effective dielectric constant of the substrate. According to table all the antenna characteristics such as return loss, gain, directivity, voltage standing wave ratio, and bandwidth are compared with respect to different sizes of the slots. The designed antenna gives a wide bandwidth of $775.4 \mathrm{MHz}$ at a resonant frequency of $5.3417 \mathrm{GHz}$ when a slot of $13 \mathrm{~mm} \times$ $11 \mathrm{~mm}$ is made in the substrate. The voltage standing wave ratio at all the resonant frequencies received by varying the size of the slots in substrate is near to unity. So this antenna gives good performance. The relation between the percentage change in resonant frequency and the ratio(As/Ap) is used to calculate the required area of slot which is to be inserted in the original substrate to get the required resonant frequency without varying the patch size. So the fabrication error can be removed by making a slot in the substrate without varying the patch of the size.

\section{References}

[1] Zhu Yongxiang, Chen Jianjun, SongXuerui, Cao Hongxi, "The Design Study of the Wide Bandwidth and High Gain RFID Microstrip Patch Antenna", Third IEEE International Conference on Intelligent System Design and Engineering Applications-2013.

[2] K. Jhamb L. Li K. Rambabu, "Frequency adjustable microstrip annular ring patch antenna with multi-band characteristics", IET Microwave. Antennas Propagation, 2011, Vol. 5, Issue 12, pp. 1471-1478 \& the Institution of Engineering and Technology 2011.

[3] Manvendra Singh Bhandari, Dr.Gupta " Increasing resonant frequency of Microstrip Patch Antenna by decreasing the value of dielectric constant of substrate", International Journal of Advanced Research in Computer Engineering \& Technology Volume 1, Issue 5, July 2012

[4] Alix Rivera-Albino, Constantine A. Balanis, "Gain enhancement in microstrip antenna using hybrid substrates," IEEE Antennas and Wireless Propagation Letters, Vol. 12, 2013

[5] Bilal Ahmed, Ilyas Saleem, "Analytical Study on Effects of Substrate Properties on the Performance of Microstrip Patch Antenna", International Journal of Future Generation Communication and Networking, Vol.5,No.4,December, 2012 